\title{
Determinação da digestibilidade intestinal de alimentos pela técnica de três estágios
}

\section{Determination of intestinal digestibility of feeds by three-steps technique}

\author{
Elzânia Sales Pereira ${ }^{1 *}$; Alex Martins Varela de Arruda ${ }^{2}$; Ivone Yurika Mizubuti³; \\ Arturo Bernardo Selaive Villarroel ${ }^{1}$; Patrícia Guimarães Pimentel ${ }^{4}$
}

\begin{abstract}
Resumo
O objetivo deste trabalho foi estimar a digestibilidade intestinal da proteína não-degradada no rúmen (PNDR), de alimentos, por intermédio da técnica de três estágios. Os alimentos avaliados foram o farelo de soja, farelo de trigo, casca de soja, farinha de carne e farinha de peixe. Os alimentos foram inicialmente incubados no rúmen por 16 horas, para determinação da PNDR. O resíduo foi submetido à digestão com solução de pepsina, durante 1 hora, e solução de pancreatina a $38^{\circ} \mathrm{C}$, durante 24 horas. Em seguida, esses resíduos foram analisados para nitrogênio total (NT). A estimativa da PNDR variou de 22,07\% a 91,30\% e a digestibilidade intestinal da PNDR de $35,13 \%$ a $80,67 \%$. A casca de soja e a farinha de carne apresentaram melhor digestibilidade intestinal e o farelo de trigo apresentou a menor digestibilidade. Embora alguns sistemas de adequação de dietas para ruminantes considerem a digestibilidade intestinal da proteína dietética como sendo constante, os resultados encontrados neste trabalho sugerem que a mesma possui variação entre os diferentes alimentos.
\end{abstract}

Palavras-chave: Avaliação de alimentos, nutrição, ruminantes, técnica in vitro

\begin{abstract}
The objective of this work was to estimate the intestinal digestibility of rumen-undegradable protein (RUDP) of feeds by a three-steps procedure. The evaluated feeds were the soybean meal, wheat meal, soybean peel, meat flour and fish flour. Firstly, the feeds were incubated in rumen during 16 hours to determine the rumen-undegradable protein. The residue was submitted to the digestion with pepsin solution during 1 hour, and pancreatic solution during 24 hours at $38^{\circ} \mathrm{C}$. Soon after, those residues were analyzed for total nitrogen (TN). The estimate of RUDP ranged of $22.07 \%$ to $91.30 \%$ and the intestinal digestibility of RUDP ranged from $35.13 \%$ to $80.67 \%$. The soybean peel and the meat flour presented better intestinal digestibility, and the wheat meal presented the lowest digestibility. Although some formulation systems of diets for ruminant consider the intestinal digestibility of dietary protein as being constant, the data obtained in this work suggest that there are variation among the different feeds.

Key words: Evaluation of feeds, in vitro technique, nutrition, ruminant
\end{abstract}

1 Professor da Universidade Federal do Ceará (UFC), Depto. de Zootecnia, Fortaleza - CE. E-mail: elzania@hotmail.com.

2 Professor da Universidade Federal Rural do Semi Árido (UFERSA), Depto. de Ciência Animal, Mossoró, RN.

3 Professora da Universidade Estadual de Londrina (UEL), Depto. de Zootecnia, Londrina - PR. Pesquisadora do CNPq.

4 Pesquisadora da Universidade Federal do Ceará (UFC), Depto. de Zootecnia, Fortaleza-CE. Bolsista do Programa de DCR, FUNCAP/CNPq.

* Autor para correspondência 


\section{Introdução}

A determinação do valor nutritivo de alimentos destinados aos ruminantes tem sido alvo de contínuos trabalhos de pesquisa, sendo constante a procura de metodologias acuradas e simples para estimar a qualidade dos alimentos. Os objetivos básicos destas metodologias consistem nas predições dos valores protéicos e energéticos dos alimentos para que atendam a demanda gerada pelas funções produtivas dos animais em dado estágio fisiológico. O problema essencial é a busca do entendimento em bases mecanicistas das relações entre a composição bromatológica, a disponibilidade de energia e proteína e as respostas esperadas nos animais.

A principal vantagem dos animais ruminantes em relação aos não-ruminantes é a boa utilização de alimentos fibrosos, a qual ocorre através da fermentação pré-gástrica realizada pela microbiota ruminal. Porém, apresentam como desvantagens a perda de energia na forma de metano e a transformação de aminoácidos essenciais em compostos mais simples pelos microrganismos ruminais.

Dentre os microrganismos ruminais, destacamse os que fermentam carboidratos estruturais e aqueles que fermentam carboidratos não estruturais. O primeiro grupo tem como principal fonte protéica a amônia e apresenta um crescimento lento. Os microrganismos que fermentam carboidratos não estruturais apresentam um crescimento mais rápido, e podem utilizar, além da amônia, peptídeos e aminoácidos como fonte de nitrogênio (RUSSEL; O CONNOR; FOX, 1992).

Os microrganismos ruminais dependem de esqueletos de carbono, disponibilidade de energia e de um concomitante fornecimento de amônia e peptídeos para que haja síntese microbiana. Aliado a isso, a disponibilidade de carboidratos no rúmen é muito importante e tem grande efeito sobre a utilização dos compostos nitrogenados, pois as bactérias ruminais podem incorporar os aminoácidos e fermentá-los como fonte de energia. Através da manipulação da relação volumoso:concentrado é possível alterar os processos fermentativos e maximizar a eficiência de síntese microbiana, bem como a eficiência de utilização dos nutrientes dietéticos. O crescimento microbiano depende da transferência de energia da fermentação de carboidratos para o processo biossintético, por exemplo, de síntese de proteína microbiana (RUSSELL; O CONNOR; FOX, 1992).

O processo catabólico (fermentação de carboidratos) é completamente vinculado ao processo anabólico (síntese microbiana) via ATP. Se a taxa de produção de ATP excede a taxa de utilização, ocorre desacoplamento energético e a energia do ATP é dissipada como calor através de ciclos fúteis de íons pela membrana celular. Isto ocorre quando a disponibilidade de $\mathrm{N}$ é extremamente alta, e a de minerais, como $\mathrm{S}$ e $\mathrm{P}$ é muito baixa ou deficiente (NOCEK; RUSSELL, 1988). Geralmente, quando carboidratos são limitantes, os aminoácidos dietéticos são usados como fonte de energia, ocorrendo acúmulo de amônia (VAN SOEST, 1994). Portanto, a adição de carboidratos, além de promover síntese de proteína microbiana, exerce um efeito poupador de aminoácidos (NOCEK; RUSSELL, 1988).

Segundo Pereira et al. (2000), existe uma diferença marcante, conforme a espécie, em relação à dependência dietética dos nutrientes: (1) plásticos (proteínas); (2) energéticos (proteínas, carboidratos e lipídios); (3) inorgânicos ou minerais; e, (4) vitaminas. A maioria dos microrganismos sintetiza aminoácidos a partir de precursores simples como a amônia; entretanto, os animais superiores não sintetizam os aminoácidos essenciais.

Os requerimentos em proteína metabolizável dos ruminantes são atendidos pela proteína microbiana produzida no rúmen, pela proteína dietética que escapa a fermentação ruminal e pela proteína endógena. A proteína microbiana contribui com $50 \%$ ou mais dos aminoácidos disponíveis para absorção no intestino delgado, sendo esta, considerada uma fonte protéica de boa qualidade. Por outro lado, a proteína dietética não degradada no rúmen apresenta 
composição em aminoácidos e digestibilidade intestinal variável com a fonte (BRODERICK, 1995).

A proteína microbiana é relativamente constante em sua composição, portanto, a única alternativa para alteração do perfil em aminoácidos que atinge os intestinos é por meio do aumento de fontes protéicas que escapam à degradação ruminal. Entretanto, a utilização de fontes protéicas que apresentam baixos níveis de degradação ruminal, em substituição às fontes de maior degradação, na maioria dos estudos, tem resultado em ausência de respostas ou até respostas negativas no desempenho dos animais. As possíveis explicações para este fato seriam a redução da síntese de proteína microbiana em função da inclusão de fontes de proteína não degradada no rúmen (PNDR) com perfil pobre em aminoácidos essenciais e/ou com baix digestibilidade intestinal, ou dietas controle elevadas em PNDR (CLARK; KLUSMEYER; CAMERON, 1992; SCHWAB, 1996).

Alguns sistemas de adequação de dietas para ruminantes consideram a digestibilidade intestinal da PNDR constante para todos os alimentos. O Cornell Net Carbohydrate and Protein System (CNCPS), conforme Sniffen et al. (1992), considera que as frações protéicas possuem digestibilidade intestinal constante. Entretanto, em alguns trabalhos tem se verificado que os alimentos diferem grandemente na quantidade de PNDR digestível no intestino delgado (CALSAMIGLIA; STERN, 1995; VALADARES FILHO, 1997; CABRAL et al., 2001) e, desta forma, a utilização de valor fixo para digestibilidade intestinal da PNDR para todos os alimentos pode resultar em sérios erros de predição na ingestão de PNDR e no desempenho animal (CABRAL et al., 2001). O NRC - National Research Council (2001), recomenda usar valores de digestibilidade intestinal da PNDR específicos para cada alimento.

Vários estudos alternativos tem sido desenvolvidos para as estimativas da digestibilidade intestinal da PNDR, dentre os quais se destacam a técnica de sacos de náilon móveis (HVELPLUND, 1985), a determinação do nitrogênio insolúvel em detergente ácido (GOERING et al., 1972), e procedimentos enzimáticos (BRITTON et. al., 1986 apud CALSAMIGLIA; STERN, 1995). Entretanto, esses métodos apresentam algumas desvantagens em relação à simulação das condições fisiológicas dos ruminantes, tais como: não incluem o potencial efeito da fermentação ruminal; demandam mais tempo e são onerosos, e ainda, não podem ser aplicados a uma grande variedade de alimentos, além de não refletirem acuradamente as diferenças na digestão intestinal entre os alimentos.

Calsamiglia e Stern (1995) desenvolveram a técnica dos três estágios in vitro para estimar a digestibilidade intestinal da PNDR em animais ruminantes. A técnica tem como vantagens a simulação das condições fisiológicas dos ruminantes, sendo relativamente rápida, não onerosa, simples e pode ser utilizada para uma grande variedade de alimentos protéicos.

O objetivo deste trabalho foi estimar a digestibilidade intestinal da proteína não degradada no rúmen de alguns alimentos protéicos comumente utilizados no Brasil através da técnica de três estágios.

\section{Material e Métodos}

A incubação in situ foi realizada na Fazenda Escola e Laboratório de Nutrição Animal do Departamento de Zootecnia do Centro de Ciências Agrárias da Universidade Estadual de Londrina (UEL), utilizando-se 4 animais fistulados no rúmen e providos de cânulas ruminais. As incubações in vitro foram realizadas no Laboratório de Nutrição Animal do Centro de Ciências Agrárias da Universidade Estadual do Oeste do Paraná (UNIOESTE)Campus de Marechal Cândido Rondon -PR.

Foram avaliados cinco tipos de alimentos: farelo de soja, farelo de trigo, casca de soja, farinha de carne e farinha de peixe, os quais foram analisados para matéria seca (MS), proteína bruta (PB), matéria mineral (MM), matéria orgânica (MO) e extrato etéreo (EE), seguindo os procedimentos padrões 
(ASSOCIATION OF OFFICIAL ANALYTICAL CHEMISTS - AOAC, 1990), e fibra em detergente neutro (FDN) e fibra em detergente ácido (FDA) segundo Van Soest, Robertson e Lewis (1991). A composição bromatológica dos alimentos está apresentada na Tabela 1.

A estimativa da digestibilidade intestinal da PNDR dos alimentos foi determinada através da técnica de três estágios in vitro, desenvolvida por Calsamiglia e Stern (1995). Inicialmente, cerca de 1,5 g de amostra dos concentrados protéicos foram moídos em peneira de $2 \mathrm{~mm}$, conforme sugerido por Nocek e Russel (1988), e posteriormente foram incubados no rúmen durante 16 horas através de sacos de náilon. A quantidade de amostra incubada foi dependente do seu teor de $\mathrm{N}$, pois o resíduo da incubação ruminal continha no mínimo $60 \mathrm{mg}$ de $\mathrm{N}$ residual. Após a incubação ruminal, os sacos foram lavados em água corrente até que a água de enxágüe ficasse clara, e então foram colocados em estufa de ventilação forçada durante 48 horas a $55^{\circ} \mathrm{C}$.

Tabela 1. Porcentagem de matéria seca (MS), proteína bruta (PB), matéria mineral (MM), extrato etéreo (EE) e fibra em detergente neutro (FDN) dos alimentos

\begin{tabular}{lccccc}
\hline \multirow{2}{*}{ Alimentos } & MS (\%) & \multicolumn{4}{c}{ Porcentagem na MS } \\
\cline { 3 - 6 } & & PB & MM & EE & FDN \\
\hline Farelo de Soja & 93,64 & 47,74 & 6,50 & 2,21 & 13,05 \\
Farelo de Trigo & 94,47 & 18,84 & 4,25 & 3,34 & 36,97 \\
Casca de Soja & 94,57 & 16,25 & 8,06 & 5,09 & 52,28 \\
Farinha de Carne & 92,14 & 89,86 & 38,92 & 12,38 & - \\
Farinha de Peixe & 89,63 & 68,73 & 13,93 & 9,98 & - \\
\hline
\end{tabular}

Para a simulação da digestão intestinal da proteína dos resíduos, foi determinada a concentração de nitrogênio destes, e com base nestes valores, foram pesados os resíduos que proporcionaram aproximadamente $15 \mathrm{mg}$ de nitrogênio e colocados em erlemeyers de $125 \mathrm{~mL}$. Posteriormente, estes foram incubados com $10 \mathrm{~mL}$ de uma solução $0,1 \mathrm{~N}$ de $\mathrm{HCl}$ contendo $1 \mathrm{~g} / \mathrm{L}$ de pepsina $(\mathrm{pH}=1,9)$ durante uma hora a $38^{\circ} \mathrm{C}$. Em seguida, foram adicionados $0,5 \mathrm{~mL}$ de solução $1 \mathrm{~N}$ de $\mathrm{NaOH}$ para neutralização do $\mathrm{pH}$, e 13,5 mL de solução de pancreatina $(0,5 \mathrm{M}$ de solução de $\left.\mathrm{KH}_{2} \mathrm{PO}_{4}, \mathrm{pH}=7,8\right)$ contendo 50 ppm de thymol, para prevenir o crescimento microbiano, e $3 \mathrm{~g} / \mathrm{L}$ de pancreatina, durante 24 horas. Ao final da digestão, os resíduos foram imediatamente filtrados em papel filtro, lavados com $400 \mathrm{~mL}$ de água destilada e o nitrogênio residual determinado através do método Kjeldahl (AOAC, 1990). A digestibilidade intestinal da PNDR, em porcentagem, foi calculada como sendo a quantidade de nitrogênio digerido após incubação com solução de pepsina e pancreatina multiplicado por 6,25 , sendo este dividido pela quantidade de proteína incubada, e multiplicado por 100.

\section{Resultados e Discussão}

Os valores da degradação ruminal e da digestão intestinal da PB dos alimentos estão expressos na Tabela 2, onde se nota que a percentagem da PDR variou de 7,54 a 74,98\% da PB para farinha de carne e farelo de trigo, respectivamente, estando estes valores de acordo com os sugeridos pela literatura 
(CABRAL et al., 2001). As estimativas da PNDR para o farelo de soja, farelo de trigo e farinha de peixe foram semelhantes às obtidas por Hernandez et al. (2002), que relataram valores de 49,22\%, $23,39 \%, 84,26 \%$, respectivamente.

Como esperado, as fontes protéicas de origem animal apresentaram menor degradação ruminal do que as fontes de origem vegetal, sendo portanto, indicadas como fontes de alto escape ruminal. Entretanto, a utilização destas fontes depende da digestão intestinal de sua proteína (Tabela 2, Figuras 1 e 2). Observa-se pela Tabela 2 que as fontes protéicas de origem vegetal (farelo de trigo e farelo de soja) apresentaram elevada degradação ruminal, merecendo a atenção especial quando da sua utilização em proporção significativa em rações de ruminantes. Podem ocorrer grandes perdas de $\mathrm{N}$ no rúmen, sendo necessário a inclusão de fontes energéticas de rápida degradação no rúmen.

Tabela 2. Teores de proteína bruta $(\mathrm{PB})$, proteína degradada no rúmen (PDR), proteína não degradada no rúmen (PNDR) para 16 horas de incubação ruminal, digestibilidade intestinal da PNDR (DI) e PNDR digestível no intestino delgado $\left(\mathrm{PNDR}_{\mathrm{D}}\right)$, de alguns alimentos protéicos

\begin{tabular}{lccccc}
\hline Alimentos & PB & PDR & PNDR & DI & PNDR \\
\cline { 3 - 4 } & $(\% \mathrm{MS})$ & \multicolumn{2}{c}{$(\% \mathrm{~PB})$} & & \\
\cline { 1 - 3 } & & & & & \\
Farelo de Soja & 47,74 & 51,20 & 48,80 & 73,06 & 41,24 \\
Farelo de Trigo & 18,84 & 74,98 & 25,02 & 35,13 & 8,71 \\
Casca de Soja & 16,25 & 47,22 & 52,78 & 80,67 & 39,25 \\
Farinha de Carne & 89,86 & 7,54 & 92,60 & 78,23 & 73,25 \\
Farinha de Peixe & 68,73 & 12,03 & 87,97 & 71,37 & 64,23 \\
\hline
\end{tabular}

Com relação à digestão intestinal da PNDR (Figura 1), os valores encontrados neste estudo variaram de 35,13 a $80,67 \%$ para o farelo de trigo e casca de soja, respectivamente. As digestibilidades intestinais da PNDR para o farelo de soja, farelo de trigo e farinha de peixe foram similares aos registrados por Cabral et al. (2001), que encontraram valores de $82,68 \%, 38,18 \%$ e $73,37 \%$, respectivamente.

O farelo de soja apresentou uma digestibilidade intestinal de $73,6 \%$, estando este valor abaixo dos obtidos por Calsamiglia e Stern (1995), Cabral et al. (2001), e Hernandez et al. (2002), que encontraram valores de $82,8 \%, 82,7 \%$, e $84,67 \%$, respectivamente. Porém, todos estes valores estão abaixo daqueles verificados por Ramos et al. (1996) e De Boer, Murph e Kennelly (1987), que encontraram valores da ordem de 97,2 e $99,3 \%$, respectivamente. A variação relatada pela literatura possivelmente pode ser atribuída à variação das diferentes fontes utilizadas, e também às falhas nos diferentes métodos de determinação dessa digestibilidade. Com relação a PNDR, o farelo de soja apresentou um valor de 53, $82 \%$, estando um pouco abaixo daquele encontrado por Hernandez et al. (2002), da ordem de 49,22\%. Entretanto, o NRC (1985) considerou valores de 14 a $82 \%$ para a PNDR do farelo de soja.

Segundo Santos et al. (1998), citados por Cabral et al. (2001), a superioridade do farelo de soja quanto à qualidade de sua proteína tem sido comprovada em estudos nos quais este suplemento tem sido substituído por fontes protéicas de altos níveis de 
escape ruminal, onde foram verificados benefícios pela suplementação dessas fontes. Tal fato é explicado pela redução da síntese de proteína microbiana e redução do seu fluxo para o intestino delgado.

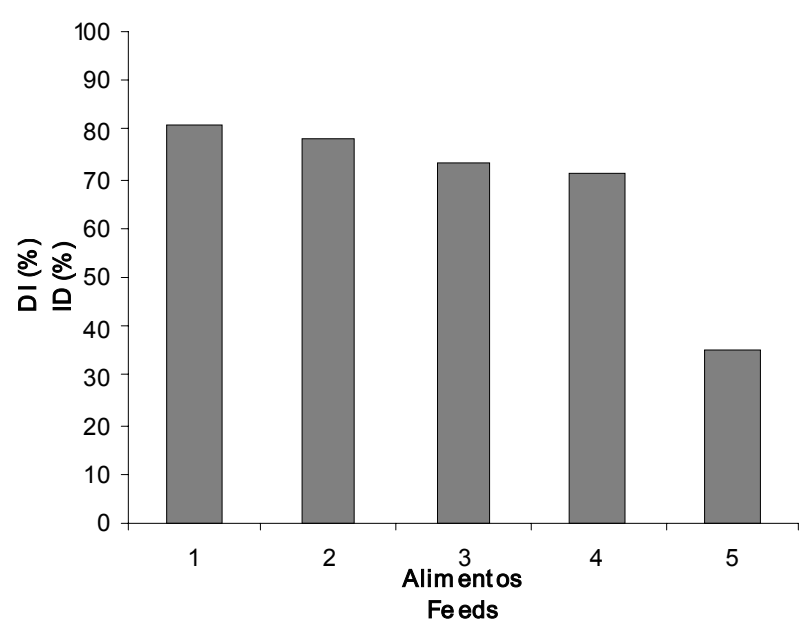

Figura 1. Digestibilidade intestinal (DI) da PNDR da casca de soja (1), farinha de carne (2), farelo de soja (3), farinha de peixe (4) e farelo de trigo (5).

O farelo de trigo apresentou uma degradação ruminal de 74,98\%, estando este valor de acordo com os encontrados por Cabral et al. (2001) e Hernandez et al. (2002), que encontraram valores para a PDR da ordem de 76,95 e 76,61\%, respectivamente. A PNDR encontrada neste estudo $(22,07 \%)$ para o farelo de trigo está em concordância com os valores encontrados por Cabral et al. (2001), Hernandez et al. (2002), e também está de acordo com aqueles sugeridos pelo NRC (1989), que relatou um valor de $22 \%$ para esta variável. Com relação a digestibilidade da PNDR, o farelo de trigo apresentou uma digestibilidade intestinal de $35,13 \%$, valor este que é similar ao encontrado por Cabral et al. (2001), e inferior ao encontrado por Hernandez et al. (2002), que observaram valores de 38,18 e 46,47\%. Esta baixa digestibilidade intestinal implica em menor disponibilidade de aminoácidos para absorção no intestino. Tal fato é atribuído à elevada degradação ruminal deste alimento, podendo ser sugerido que a proteína que escapa a degradação ruminal esteja associada à porção fibrosa, o que explica a baixa digestão no intestino delgado.

Com relação às fontes de origem animal, observou-se que as degradações ruminais das farinhas de carne e peixe foram da ordem de 7,54 e $12,03 \%$, respectivamente, estando estes valores de acordo com os encontrados por Cabral et al. (2001).

A farinha de peixe apresentou uma degradação ruminal $(12,03 \%)$ similar àquela encontrada por Hernandez et al. (2002) e Cabral et al. (2001), que encontraram valores de 15,74 e $11,07 \%$, respectivamente. A digestibilidade intestinal da PNDR da farinha de peixe $(71,37 \%)$ encontrada neste estudo foi inferior aos valores encontrados por Coneglian et al. (2003) e Hernandez et al. (2002), que encontraram valores de 79,92 e 79,76\%, respectivamente; e, por outro lado, foi similar ao valor encontrado por Cabral et al. (2001).

A farinha de carne proporcionou o maior teor de proteína não degradada no rúmen e digestível no intestino $\left(\right.$ PNDR $\left._{\mathrm{D}}\right)$, da ordem de 73,25\%. Fato esse que pode ser explicado devido ao seu elevado teor de proteína bruta, ao elevado escape do rúmen e a sua elevada digestão intestinal.

Embora alimentos como o farelo de soja, casca de soja, farinha de carne e farinha de peixe tenham apresentado alta digestibilidade intestinal, alguns autores, citados por Cabral et al. (2001), sugerem que a melhora no desempenho de vacas leiteiras de alta produção, adicionalmente à digestão intestinal, depende do perfil de aminoácidos dessas fontes, o qual deve complementar o perfil da proteína microbiana (CHEN et al., 1993; CLARK; KLUSMEYER; CAMERON, 1992; SCHWAB et al., 1992; BRODERICK, 1995). 


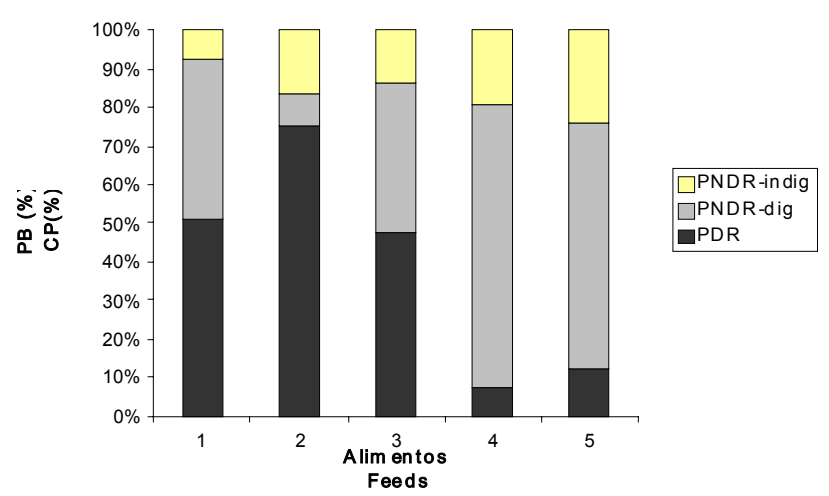

Figura 2. Proporções relativas da proteína degradada no rúmen (PDR), da proteína não degradada no rúmen, digestível (PNDR dig.) e da proteína não degradada no rúmen, indigestivel (PNDR indig.) no intestino delgado, do farelo de soja (1), farelo de trigo (2), casca de soja (3), farinha de carne (4) e farinha de peixe (5).

Vários experimentos citados na literatura têm demonstrado que os aminoácidos lisina e metionina são os primeiros limitantes à produção de leite e à síntese de proteína do leite (SCHWAB, 1996). Para bezerros em crescimento, sugere-se a metionina, lisina e treonina como primeiro, segundo e terceiro aminoácidos limitantes, respectivamente (RICHARDSON; HATFIELD, 1978). Em vitelos, consideram-se limitantes os aminoácidos sulfurados, a lisina e, provavelmente, a treonina (WILLIAMS, 1994).

Schwab et al. (1992), comparando o perfil aminoacídico de várias fontes protéicas, constatou que a proteína microbiana apresentou o melhor perfil e a melhor relação lisina:metionina.

O farelo de soja apresentou concentração média de lisina e de média a baixa de metionina, mas apresentou equilíbrio entre os aminoácidos. A farinha de peixe apresentou balanço equilibrado em lisina e metionina, sendo indicada como uma fonte capaz de promover melhora no balanço de aminoácidos no duodeno e, conseqüentemente, na produção de vacas leiteiras de alta produção.

Este estudo confirmou os resultados obtidos por De Boer, Murph e Kennelly (1987), Van Straalen e Tamminga (1990), Kendall; Ingalls; Boila (1991), Castillo (1992), Valadares Filho (1995), Hernandez et al. (1998) e Hernandez et al. (2002), os quais constataram que a digestibilidade intestinal da PNDR não foi constante.

\section{Conclusão}

A técnica de três estágios para estimar a digestibilidade intestinal da proteína degradada no rúmen, dos alimentos protéicos, se mostrou adequada e em concordância com os resultados relatados pela literatura.

A casca de soja e a farinha de carne foram os alimentos que apresentaram a maior digestibilidade intestinal, e o farelo de trigo a menor. No entanto, o uso de qualquer um desses alimentos na formulação de dietas para ruminantes deve levar em conta o perfil aminoacídico desses alimentos.

Embora alguns sistemas de adequação de dietas para ruminantes considerem que a PNDR apresenta digestibilidade intestinal constante entre os alimentos, os resultados registrados neste estudo sugerem que a digestibilidade intestinal da proteína não degradada no rúmen é variável.

\section{Referências}

ASSOCIATION OF OFFICIAL ANALYTICAL CHEMISTS - AOAC. Official methods of analysis. 15.ed. Virginia: Arlington, 1990.

BRITTON, R. A.; KLOPFENSTEIN, T. J.; CLEALE, R.; GOEDEKEN, F.; WILKERSON, V. Methods of estimating heat damage in protein sources. PROCEEDINGS DISTILLERS FEED CONFERENCE, 41., 1986, Cincinnati. Proceedings... Cincinnati, 1986. p. 67.

BRODERICK, G. A. Quantifying forage protein quality. In: NATIONAL CONFERENCE ON FORAGE QUALITY, EVALUATION, AND UTILIZATION, 1995, Lincoln. Proceedings... Lincoln: University of Nebrasca, 1995. p. 200-228.

CABRAL, L. S.; VALADARES FILHO, S. C.; MALAFAIA, P. A. M.; LANA, R. P.; SILVA, J. F. C.; VIEIRA, R. A. M.; PEREIRA, E. S. Estimação da digestibilidade intestinal da proteína de alimentos por intermédio da técnica de três estádios. Revista Brasileira de Zootecnia, Viçosa, v. 30, n. 2, p. 546-552, 2001. 
CALSAMIGLIA, S.; STERN, M. D. A three-step in vitro procedure for estimating intestinal digestion of protein ruminants. Journal of Animal Science, Champaign, v. 73, n. 5.p. 1459-1465, 1995.

CASTILLO, A. M. Avaliação da degradabilidade ruminal e da digestibilidade intestinal de vários alimentos, utilizando-se a técnica do saco de náilon móvel. Viçosa: UFV, 1992, 108p. Tese (Doutorado em Zootecnia) - UFV, 1992.

CHEN, K. H.; HUBER, J. T.; THEURER, C. B.; SIMAS, J.; ARMSTRONG, D. V.; WANDERLEY, R. C.; SIMAS, J. M.; CHAN, S. C.; SULLIVAN, J. L. Effect of protein quality and evaporative cooling on lactational performance of Hostein cows in hot weather. Journal of Dairy Science, Champaign, v. 76, n. 3, p. 819-825, 1993.

CLARK, J. H.; KLUSMEYER, T. H.; CAMERON, M. R. Microbial protein syntesis and flows of nitrogen fractions to the duodenum of dairy cows. Journal of Dairy Science, Champaign, v. 75, n. 8, p. 2304-2323, 1992.

CONEGLIAN, S. M.; BRANCO, A. F.; MAIA, F. J.; FERREIRA, R. A. Determinação in vitro da digestibilidade intestinal verdadeira da proteína de diferentes alimentos para ruminantes. In: ENCONTRO ANUAL DE INICIAÇÃO CIENTÍFICA, 12., 2003, Foz do Iguaçu. Anais.... Foz do Iguaçu: UNIOESTE, 2003. CD-ROM

DE BOER, G.; MURPH, J. J.; KENNELLY, J. J. Moblile nylon bag for estimating intestinal availability of rumen undegradable protein. Journal of Dairy Science, Champaign, v. 70, n. 5, p. 977-982, 1987.

GOERING, H. K.; GORDON, C. H.; HEMKEN, R. W.; WALDO, D. R.; VAN SOEST, P. J.; SMITH, L. W. Analytical estimatives of nitrogen digestibility in heat damaged forages. Journal of Dairy Science, Champaign, v. 55, n. 9 , p. 1275-1280, 1972.

HERNANDEZ, L. F. I.; BONECARRERE, S. L. M.; VIEIRA, R. A.; SANCHEZ, L. M. B. Desaparecimento ruminal e digestibilidade intestinal e total da matéria seca e proteína bruta de alguns suplementos concentrados. Revista Brasileira de Zootecnia, Viçosa, v. 27, n. 4, p. 777-782, 1998.

HERNANDEZ, L. F. I.; VALADARES FILHO. S. C.; LANA, R. P.; MANCIO, A. B.; PAULINO, M. F.; CECON, P. R.; VALADARES, R. F. D.; MAGALHÃES, K. A.; REIS, S. L. R. Avaliação de dois métodos in vitro para determinar a cinética ruminal e a digestibilidade intestinal da proteína de vários alimentos. Revista Brasileira de Zootecnia, Viçosa, v. 31, n. 1, p. 256-266, 2002.

HVELPLUND, T. Digestibility of rumen microbial protein and undegraded dietary protein estimate in the small instestine of sheep and by in sacco procedure. Acta agriculturae scandinavica. Supplementum, Stockholm, v. 25, n. 1, p. 132-144, 1985.

KENDALL, E. M.; INGALLS, J. R.; BOILA, J. R. Variability in the rumen degradability and postruminal digestion of the dry matter, nitrogen and amino acids of canola meal. Canadian Journal of Animal Science, Ottawa, v. 71, n. 5, p. 739-748, 1991.

NATIONAL RESEARCH COUNCIL - NRC. Nutrient requirements of dairy cattle. 6 . ed. Washington: National Academy Press, 1989.

Nutrient requirements of dairy cattle. 7. ed. Washinton: National Academy Press, 2001.

Ruminant nitrogen usage. Washinton: National Academy Press, 1985.

NOCEK, J. E.; RUSSELL, J. B. Protein and energy as an integrated system. Relationship of ruminal protein and carbohydrate availability to microbial synthesis and milk production. Journal of Dairy Science, Champaign, v. 71, n. 8, p. 2070-2107, 1988.

PEREIRA, E. S.; QUEIROZ, A. C.; VALADARES FILHO, S. C.; PAULINO, M. F.; ARRUDA, A. M. V.; CABRAL, L. S.; MIRANDA, L. F. Determinação das frações protéicas e de carboidratos, e taxas de degradação in vitro da canade-açúcar e farelo de algodão. Revista Brasileira de Zootecnia, Viçosa, v. 29, n. 6, p. 1887-1893, 2000.

RAMOS, S. M.; VALADARES FILHO, S. C.; SILVA, J. F. C.; LEÃO, M. I.; QUEIROZ, A. C.; ALMEIDA, R. G. Utilização da técnica do saco de nylon móvel para a determinação da digestibilidade intestinal de vários alimentos, em novilhos cecectomizados. Revista Brasileira de Zootecnia, Viçosa, v. 25, n. 4, p. 778-793, 1996.

RICHARDSON, C. R.; HATFIELD E. E. The limiting amino acid in growing cattle. Journal of Animal Science, Champaign, v. 46, n. 3, p. 740-749, 1978.

RUSSEL, J. B.; O CONNOR, J. D.; FOX, D. G. A net carbohydrate and protein system for evaluating catle diets: I. Ruminal fermentation. Journal of Animal Science, Champaign, v. 70, n. 12, p. 3551-3561, 1992.

SANTOS, F. A. P.; SANTOS, J. E. P.; THEURER, C. B.; HUBER, J. T. Effects of rúmen-undegradable protein on dairy cow performance; A 12-year literature Review. Journal of Dairy Science, Champaign, v. 81, n. 12, p. 34863502, 1998.

SCHWAB, C. G. Amino acid nutrition of the dairy cow: Current status. In: CORNELL NUTRITION CONFERENCE FOR FEED MANUFACTURES. 58., 1996, Ithaca. Proceedings... Ithaca: Cornell University, 1996. p.184-198. 
SCHWAB, C. G.; BOZAC, C. K.; WHITEHOUSE, N. L.; OLSON, V. M. Amino acid limitation and flow duodenum at four stages of lactation. 2. Extent of lisin limitation. Journal of Dairy Science, Champaign, v. 75, n. 12, p. 35033518, 1992.

SNIFFEN, C. J.; O'CONNOR, J. D.; VAN SOEST, P. J.; FOX, D. G.; RUSSELL, J. B. A net carbohydrate and protein system for evaluating cattle diets: II. Carbohydrate and protein availability. Journal of Animal Science, Champaign, v. 70, n. 12, p. 3562-3577, 1992.

VALADARES FILHO, S. C. Digestão pós-ruminal de proteínas e exigências de aminoácidos para ruminantes. In: SIMPÓSIO INTERNACIONAL DE DIGESTIBILIDADE EM RUMINANTES, 1997, Lavras. Anais... Lavras: UFLA/ FAEPE, 1997.p. 87-113

Eficiência de síntese de proteína microbiana, degradação ruminal e digestibilidade intestinal da proteína bruta, em bovinos. In: SIMPOSIO INTERNACIONAL
SOBRE EXIGÊNCIAS NUTRICIONAIS DE RUMINANTES, 1995, Viçosa. Anais... Viçosa: Universidade Federal de Viçosa, 1995. p. 355-388.

VAN SOEST, P. J. Nutritional ecology of the ruminant. Ithaca: Cornell University Press, 1994.

VAN SOEST, P. J.; ROBERTSON, J. B.; LEWIS, B. A. Methods for dietary fiber, neutral detergent fiber, and nonstarch polyssacharides in relation to animal nutrition. Journal of Dairy Science, Champaign, v. 74, n. 10, p. 35833597, 1991.

VAN STRAALEN, W. M.; TAMMINGA, S. Protein degradation of ruminant diets. In: WISEMAN, J.:COLE, D. J. A. (Ed.) Feedstuffs evaluation. London: Butterworths, 1990. p. 55-72.

WILLIAMS, A. P. Amino acid requeriments of the veal calf and beef steers. In: D'MELLO, J. P. F. (Ed.) Amino acids in farm animal nutrition. Wallingford: CAB. 1994. p. 329-350. 
